\title{
Characterization of Welding Residual Stresses with Neutron Diffraction CONF-980627--
}

\author{
X.-L. Wang, S. Spooner, C. R. Hubbard \\ Oak Ridge National Laboratory, Oak Ridge, TN 37831-6064 \\ Z. Feng \\ Edison Welding Institute, 1250 Arthur E. Adams Dr., Columbus, $\mathrm{OH} 43210$ \\ B. Taljat \\ Oak Ridge National Laboratory, Oak Ridge, TN 37831-6140
}

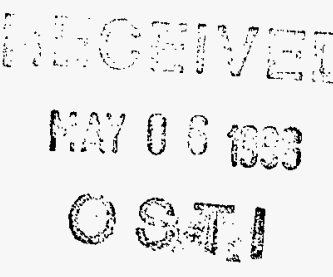

Welding residual stresses are a key concern in the fabrication and use of structural components containing welds. Residual stresses in welds are caused by nonuniform expansion and shrinkage of differently heated zones during the thermal transient of a weld pass. In some alloys, solid state phase transformations occurring during the welding transient contribute additional residual stresses. Manufacturing problems arising from welding residual stresses include cracking and dimensional distortion. During use, tensile stresses in the welded zone limit the fatigue resistance of the component under cyclic loading. In an aggressive environment, tensile welding residual stresses also create a necessary condition for stresscorrosion cracking to take place.

Neutron diffraction has been particularly useful for investigating residual stress problems in welded components. With neutron diffraction, detailed information, such as the three-dimensional spatial distribution and the orientation of the stress tensor can be determined. We have used this technique to investigate residual stresses in a variety of weld specimens, with different materials combinations, welding parameters, and geometries. The results of some of these measurements are reviewed and their bearing on practical applications is discussed below.

Multipass steel plates and the effectiveness of various stress relief methods

One of the extensively studied weld structures is multipass steel plate [1-3]. Both ferritic and austenitic plates have been studied. In the absence of a phase transformation, the spatial dependence of residual stresses in ferric and austenitic plates look similar. Fig. 1 shows the residual stress maps determined for a multipass ferritic steel plate [2] at the mid plane normal to the weld. In the longitudinal direction, the residual stresses are tensile in the fusion and heat affected zones, with a maximum reaching $600 \mathrm{MPa}$. In the transverse direction, the residual stresses remain tensile in these regions, but with smaller magnitudes. The normal stresses (perpendicular to the plate) are not shown here, since they are small, as they should be. One important feature revealed by Fig. 1 is that the maximum residual stresses are located at mid depth, rather than at the top or bottom surfaces. The use of neutron diffraction method is essential in this study to reveal the location of tensile stress maxima.

Various stress relief methods have been used to reduce residual stresses due to welding. In the past, stress relief practices relied on accumulated experience. With neutron diffraction, the effectiveness of different stress methods can be characterized quantitatively. To illustrate this point, Fig. 2 shows the longitudinal residual strain in a ferritic steel plate in the as-welded condition and after post-weld heat treatment $\left(@ 500^{\circ} \mathrm{C}\right.$ for 1 hour) [4]. As can be seen, after post-weld heat treatment, the residual strains decreased by $60 \%$, but did not vanish entirely. Higher heat treatment temperature or longer hold time is required in order to further reduce the residual stresses due to welding.
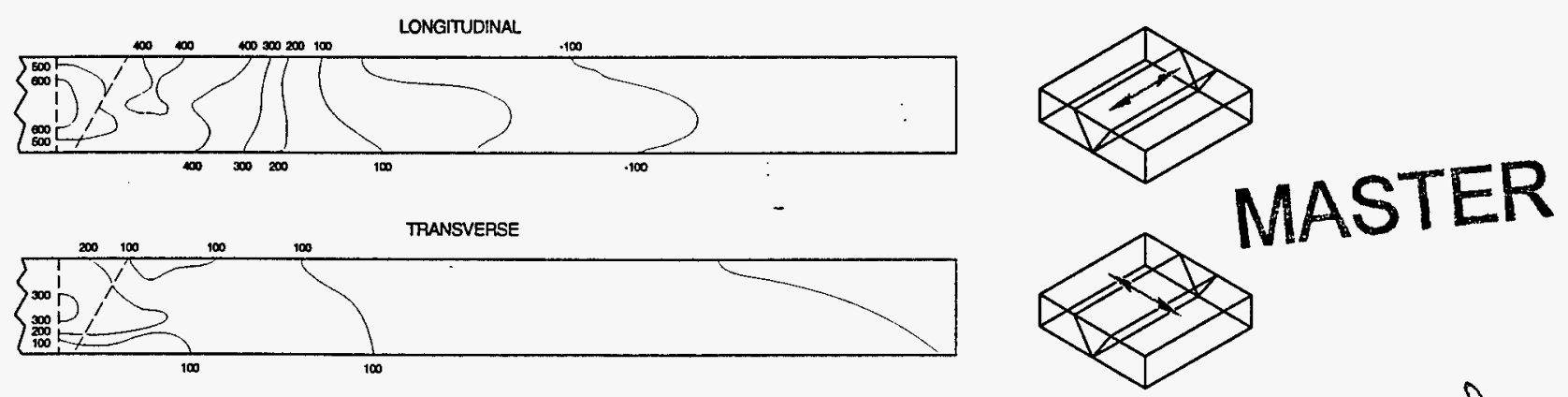

Fig. 1 Residual stress maps for a multipass ferritic steel plate at the mid plane normal to the weld.

"The submitted manuscript has been authored by a contractor of the U.S. government under contract No. DE-AC05-960R22464. Accordingly, the U.S. Government retains a nonexclusive, royalty-free license to publish or reproduce the published form of this contribution, or allow others to do so, for U.S.

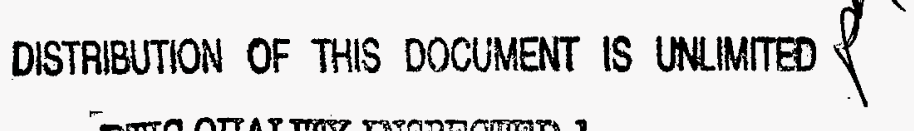
Government purposes." 


\section{DISCLAIMER}

This report was prepared as an account of work sponsored by an agency of the United States Government. Neither the United States Government nor any agency thereof, nor any of their employees, makes any warranty, express or implied, or assumes any legal liability or responsibility for the accuracy, completeness, or usefulness of any information, apparatus, product, or process disclosed, or represents that its use would not infringe privately owned rights. Reference herein to any specific commercial product, process, or service by trade name, trademark, manufacturer, or otherwise does not necessarily constitute or imply its endorsement, recommendation, or favoring by the United States Government or any agency thereof. The views and opinions of authors expressed herein do not necessarily state or reflect those of the United States Government or any agency thereof. 
Sub-harmonic vibratory treatment has been proposed as an inexpensive alternative to the conventional thermal stress relief practices. Several neutron diffraction studies have been undertaken [4-6] to quantify the effectiveness of this stress relief method. However, none of the specimens investigated so far has shown an appreciable reduction in residual stresses due to sub-harmonic vibratory treatment. Further systematic studies are needed in order to establish the benefit of sub-harmonic vibratory treatment.

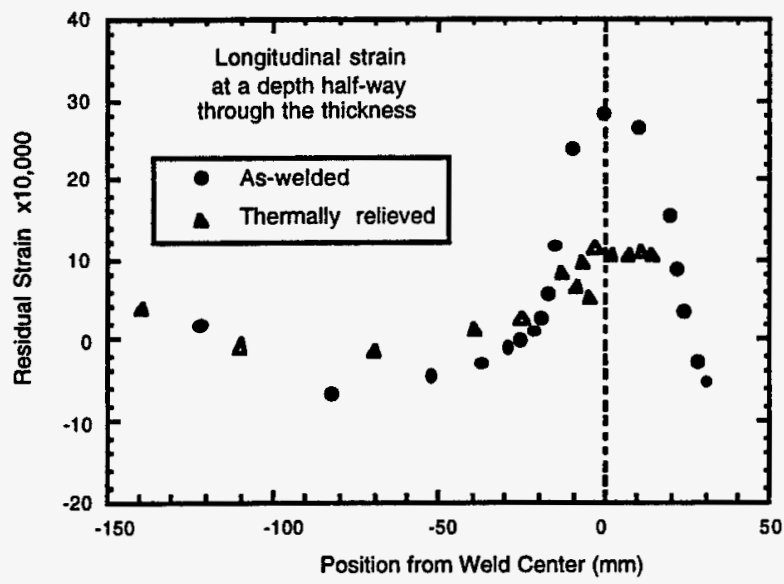

Fig. 2 Effect of thermal stress relief in a multipass ferritic steel plate.

\section{FeAl weld overlay on steel}

FeAl alloys have been shown to exhibit outstanding high-temperature oxidation/corrosion resistance and therefore have great potential for use as corrosion-resistant cladding in a variety of high-temperature structural applications. Several such FeAl alloys have been developed with improved mechanical behavior and weldability. However, producing a crack-free cladding onto, for example, a steel substrate has proven to be a challenging task. In general, special preheat and post-weid heat treatment are required. Earlier welding research revealed that while there was no hot-cracking during welding, substantial coldcracking occurred during cooling of the weld overlay. This observation points to the residual stresses which developed during cooling as a result of the temperature difference and thermal expansion mismatch between the FeAl deposit and the steel substrate. To understand the nature and development of these residual stresses, we have initiated a systematic investigation combining neutron diffraction measurements and finite element modeling [7-8].

A model system made of a short single-pass FeAl weld deposited on a $21 /{ }_{4} \mathrm{Cr}-1 \mathrm{Mo}$ steel substrate was investigated. Detailed measurements were made in the steel substrate as well as in the FeAl weld. The experimentally determined residual stresses show a strong spatial dependence along the weld direction, especially in the vicinity of the weld ends, which cannot be described within the context of a two- dimensional cross-sectional model. To model these experimental data, a three-dimensional (3D) finite element model was developed [8]. Fig. 3 shows a comparison of the experimental longitudinal strain map obtained at $2 \mathrm{~mm}$ depth in the steel substrate with the results of $3 D$ finite element calculations. With the 3D model, principal features of the experimental data are well reproduced. One of the characteristics of the 3D model is the prediction of a significant in-plane shear stress/strain near the weld ends. Subsequent neutron diffraction measurements made in these regions confirmed this prediction, further validating the finite element model. While there is still room for the model to be improved, mainly for numerical accuracy, already the model can be used to examine the effect of different welding practices as well as property mismatch between the weld metal and substrate, at least on a semiquantitative scale. In addition to weld overlay applications, the model can also be used to simulate residual stresses in repair weld situations.

Applying a post-weid heat treatment at $700^{\circ} \mathrm{C}$ for 2 hrs. eliminates most of the residual stresses accumulated during welding [7]. Upon cooling from the heat treatment temperature, another type of residual stress develops due primarily to the thermal expansion mismatch between the FeAl alloy and the steel substrate. This type of residual stress was labeled as the joining stress, since the overall stress patterns look similar to those in brazed ceramic-metal joints. As in the case of brazed ceramic-metal joints, joining stresses in FeAl weld overlay on steel are well understood within the framework of a simple elasto-plastic finite element model [7].

\section{Weld overlay tubing}

Black liquor recovery boilers are an essential component in kraft pulp mills. They provide a means for the mills to recover chemicals used in the pulping process and to produce process steam which generates a significant portion of the electricity required for mill operation. Because the boiler atmosphere is quite corrosive, composite tubing of stainless steel on carbon steel is used in some areas to provide additional corrosion resistance. Typically, composite tubes are made by co-extrusion at elevated temperatures, followed by cold reduction, anneating, and straightening. Recently, there has been growing interest in an alternative manufacturing technology, where the corrosion resistant layer is applied to the carbon steel tube by welding. A fundamental issue associated with weld overlay tubes is that large tensile residual stresses are present due to thermal shrinkage of the weld metal following the deposition. The tensile residual stresses in the weld layer could cause degradation by stress-corrosion cracking and contribute to thermal fatigue when the tubes are subjected to thermal cycling. Thus, there is a critical need to quantify these residual stresses and look for ways to minimize them. 
Experimental Data

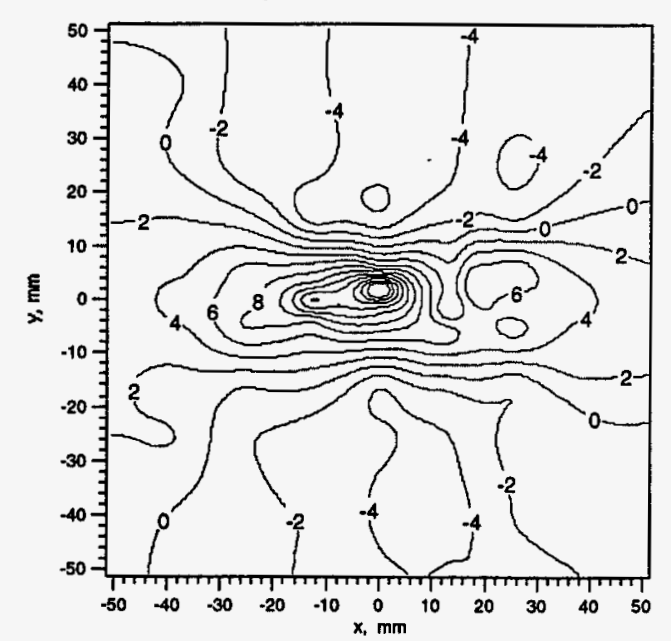

Finite Element Modeling

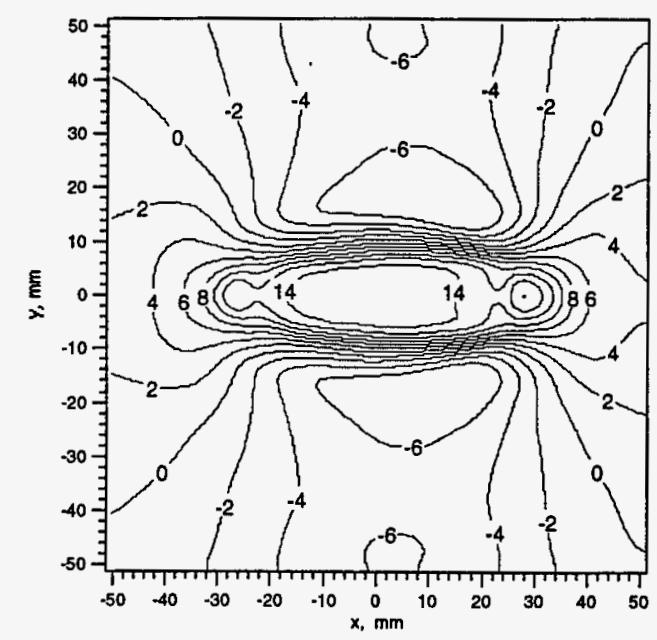

Fig. 3 A comparison of calculated and experimentally determined longitudinal strain distribution in a FeAl weld overlay on steel. The steel substrate is a square plate with a lateral dimension of $102 \mathrm{~mm}$ and a thickness of $12.4 \mathrm{~mm}$, The FeAl weld, located in the middle of the plate, is approximately $55 \mathrm{~mm}$ long, 9 $\mathrm{mm}$ wide, and $1 \mathrm{~mm}$ in thickness. The strains are in units of $10^{-4}$.

The specimen under study was a 2.5-in. OD carbon steel tube covered with a layer of alloy 625 weld overlay [9]. The measured through-thickness residual stress profile is shown in Fig. 4. Tensile stress regions were observed not only in the weld metal but also in the heat-affected zone in the carbon steel. The maximum tensile stress was located in the weld overlay layer and amounted to $360 \mathrm{MPa}$, about $75 \%$ of the $0.2 \%$ yield strength of the weld metal.

To gain insight into the thermal-mechanical process following the weld deposition, a finite element analysis was conducted [10] in parallel with the neutron diffraction work. The analysis used an uncoupled approach, i.e., the thermal analysis was performed first and then, based on the calculated temperature gradients, the mechanical state (including residual stresses) was calculated. The results of finite element calculations are also plotted in Fig. 4. Overall, the modeling results are in satisfactory agreement with the experimental data, although the hoop strain (stress) seems to have been overestimated by the finite element model. The finite element analysis indicates that the entire weld overlay layer plus part of the carbon steel yielded during cooling. The calculated plastic strain in the carbon steel shows a sharp increase (with a maximum of approximately 0.3$0.35 \%$ ) within $0.2 \mathrm{~mm}$ from the interface, consistent with microstructure observations and hardness data.

The large residual stresses in the weld overlay could potentially pose a serious problem for applications of weld overlay tubes as corrosion-resistant materials. Fortunately, further neutron diffraction studies [10] have demonstrated that residual stresses in as-welded overlay tubes can be reduced to almost zero by applying a post-weld heat treatment at $900^{\circ} \mathrm{C}$ for $20 \mathrm{~min}$. This is because high temperature heat treatment eliminates welding residual stresses and little joining stress develops during cooling since the weld overlay (alloy 625) has almost identical coefficient of thermal expansion as that of the carbon steel core.

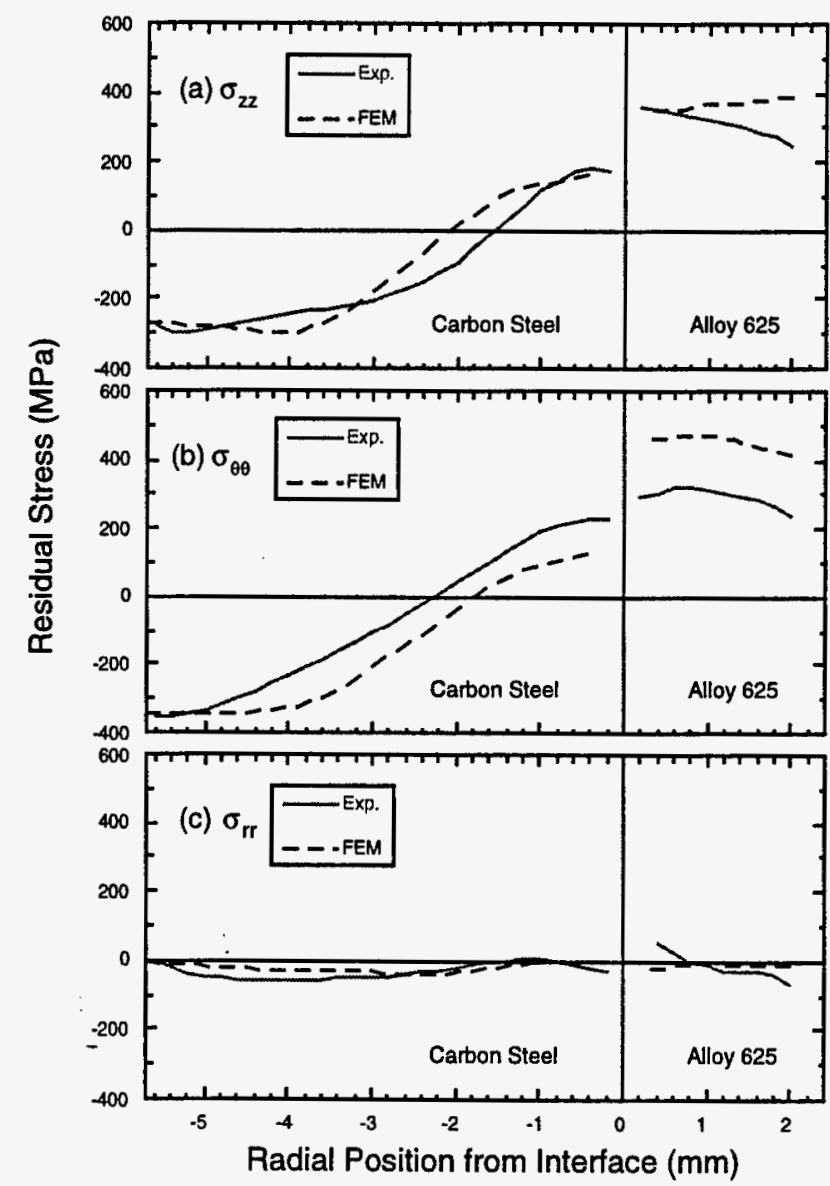

Fig. 4 Through-thickness stress profile in a spiral weld overlay tube. 
Multipass aluminum welds

High-strength aluminum alloys are an important class of materials for structural applications requiring light weight. The strengths of aluminum alloys usually derive from coldworking or precipitation hardening. However, the thermal cycling during welding often destroys the initial precipitate or work-hardening, and results in very different metallurgical conditions in the fusion and heat-affected zones. This leads to considerable uncertainties in modeling the welding residual stresses in these regions. The use of mismatched filler metal compounds these uncertainties.

Neutron diffraction was used to determine residual stresses in a thick-section aluminum plate [11]. The specimen was a 1-in. thick Al-2519 plate (24-in. long, 18-in. wide) welded in six passes with Al-2219 filler metal. Three orthogonal strain components, in longitudinal, transverse, and normal directions, respectively, were mapped in the middle cross-section plane normal to the weld.

In contrast to steel welds where residual stresses (or strains) show a peak in the middle of the fusion zone, residual stresses (or strains) in aluminum welds are characterized by a double peak structure with the maxima located in the heat-affected zone. This is illustrated in Fig. 6 , which shows the transverse strain as a function of the position from the weld center. Finite element analysis indicates that the suppression of residual stresses in the fusion zone was attributable to the properties of the undermatching (lower yield strength) filler metal and softening of the fusion zone during the welding transient.

The neutron diffraction results at the top surface of the welded plate compared well with independent blind-hole drilling measurements. The general trend and magnitudes of the complex residual stress distributions as experimentally determined are well accounted for by a $2 \mathrm{D}$ finite element model, although a new 3D model, based on an improved algorithm, seems to give a better agreement with the experimental results.

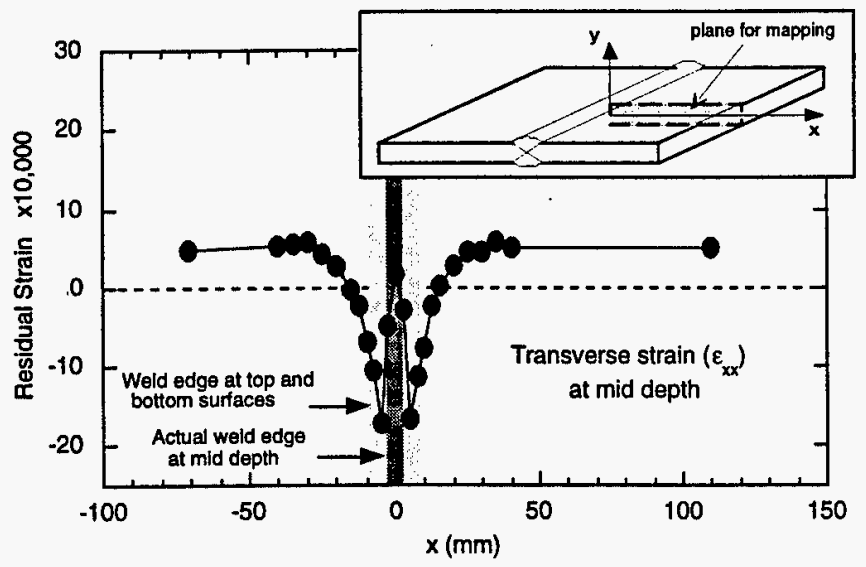

Fig. 6 Transverse strain in a thick-section aluminum plate.

\section{Summary}

Neutron diffraction has proven to be a powerful tool for experimental study of welding residual stresses. Combined with finite element modeling, neutron diffraction provides a means to understand the development of residual stresses in welded components, and helps to develop strategies for effective stress relief. Our studies show that in most cases, finite element models account very well for the spatial dependence of measured residual stresses, but the calculated stress values always seem to differ from the experimental ones by $10-20 \%$. Further refinement of the models is needed to achieve greater accuracy in prediction of welding residual stresses.

Portions of this work were sponsored by the U.S. Department of Energy (USDOE), Assistant Secretary for Energy Efficiency and Renewable Energy, Office of Transportation Technologies, as part of the High Temperature Materials Laboratory User Program. Support was also received from USDOE, Assistant Secretary for Energy Efficiency and Renewable Energy, Office of Industrial Technologies, Advanced Industrial Materials Program. Oak Ridge National Laboratory is managed by Lockheed Martin Energy Research Corp. for USDOE under contract number DE-AC05-960R22464.

\section{References}

1. P. J. Webster, "Welding Applications of Neutron Strain Scanning," pp. 95-98 in Proc. of the 3rd Int. Conf. on Trends in Welding Research, ASM Intermational, Materials Park, Ohio, USA (1993).

2. J. H. Root, T. M. Holden, J. Schroder, C. R. Hubbard, S. Spooner, T. A. Dodson, and S. A. David, "Residual Stress Mapping in Multipass Ferritic Steel Weld," Mat. Sci. Tech., 9, 754-759 (1993).

3. S. Spooner, S. A. David, J. H. Root, T. M. Holden, M. A. M. Bourke, and J. A. Goldstone, "Residual Stress and Strain Measurements in an Austenitic Steel Plate Containing Multipass Weld, "pp. 139-143 in Proc. of the 3rd Int. Conf. on Trends in Welding Research, ASM Intemational, Materials Park, Ohio, USA (1993).

4. J. Jo, X.-L. Wang, M. J. Kleinosky, R. S. Green, C. R. Hubbard, and S. Spooner, "Evaluation of Stress Relief Treatment by Neutron and X-ray Diffraction Methods," pp. 1230-1237 in Proc. of the 4th Int. Conf. on Residual Stresses, SEM, Bethel, Connecticut, USA (1994).

5. S. Spooner, S. A. David, X.-L. Wang, C. R. Hubbard, T. M. Holden, and J. Root, "Residual Stresses in Weldments - Effect of Vibration on Stresses," pp. 409-413 in Proc. of int. Conf. on Modeling and Control of Joining Processes, T. Zacharia Ed., AWS, Miami, Florida USA (1994).

6. M. E. Fitzpatrick, L. Edwards, D. Q. Wang, M. Dutta, C. Burdett, "Neutron Diffraction Study of the Effects of Vibrational Stress Relief," to appear in Proc. of the 5th Int. Conf. on Residual Stresses.

7. X.-L. Wang, S. Spooner, C. R. Hubbard, P. J. Maziasz, G. M. Goodwin, Z. Feng, and T. Zacharia, "Residual Stress Distribution in FeAl Weld Overlay on Steel," Mat. Res. Soc. Symp. Proc., 64, 109-114 (1995).

8. Z. Feng, X.-L. Wang, S. Spooner, G. M. Goodwin, P. J. Maziasz, C. R. Hubbard, and T. Zacharia, "A Finite Element Model for Residual Stress in Repair Welds," Proc. of 1996 ASME Pressure Vessels and Piping Conf., PVP-Vol 327, 119-126 (1996).

9. X.-L. Wang, E. A. Payzant, B. Taljat, C. R. Hubbard, J. R. Keiser, and M. J. Jirinec, "Experimental Determination of the Residual Stresses in a Spiral Weld Overlay Tube," Mat. Sci. Eng., A232, 3138 (1997).

10. B. Taljat, T. Zacharia, X.-L. Wang, J.R. Keiser, Z. Feng, and M. J. Jirinec, "Residual Stresses in Weld Overlay Tubes: A Finite Element Study," Proc. of 1997 ASME Pressure Vessels and Piping Conf., PVP-Vol. 347, 83-89 (1997).

11. P. Michaeleris, Z. Feng, and X.-L. Wang, unpublished. 


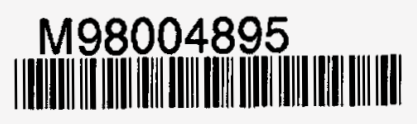

Report Number (14) 0 CNKL/CP--975,50

Publ. Date (11) DoE 199803000
Sponsor Code (18) $\frac{X E, X F}{U C-1425, \text { DOE/ER }}$
UC Category (19) 